\title{
Together We Read, Together We Learn: Examining Book Clubs as a Means of Connecting LIS to a Feminist Diversity Ethic
}

\author{
Laila Brown, University of Hawai'‘ at Mānoa, USA
}

\begin{abstract}
This article examines the significance of dialogic exploration of feminist and diversity-oriented texts in book clubs consisting of Library and Information Science (LIS) master's students at the University of Hawai'i at Mānoa. Through this research, I sought to achieve an understanding of how participation in book clubs that espouse a feminist or diversity ethic inspire members to create deeper, more insightful connections between these values and LIS. While the two book clubs under study began as separate entities with distinct memberships, participants' dual membership increased over time. The initially distinct ideals of each book club-feminism and diversity-coalesced, and a new value schema emerged in common between the two: a feminist diversity ethic. A feminist diversity ethic is a form of intersectional feminism that values experiential knowledge, the multifaceted nature of identity, respectful communication, caring, and orientation toward social justice as a means of dismantling interlocking systems of oppression. In the book clubs, this ethic encouraged the proactive search for exposure to diverse cultural and experiential paradigms through texts and stories of lived experience. Emphasis on this ethic informed book club members' approach to LIS in several ways: first, it challenged participants to define diversity and its importance in LIS; second, it fostered the deconstruction of the notion of the other; and third, it enabled participants to actualize a feminist diversity ethic within the structure of the book clubs, thus preparing them to continue this ethic in their future roles as LIS practitioners.
\end{abstract}

Keywords: book clubs; diversity; feminism; feminist diversity ethic; librarianship

Publication Type: research article

B ooks can be addictive, just as book clubs can be. Beard and Thi-Beard (2008) affirm that "reading a book is no mere act of consumption. It is a constitutive act, bound to other acts like writing, conversation, dress, travel, art, labor, and other acts that constitute the self" (p. 333). Reading is, furthermore, a generative act. This research, which focuses on collaborative discussion in two book clubs, demonstrates a nearly insatiable desire among readers to generate conversation about their reading: to ruminate on what they loved about the text and to express what they disliked, to see the text through another's perspective, and to continue the dialogue even after they have reached the book's final page and closed the cover. Beard and Thi-Beard (2008) confirm that "we need to recognize that readers select texts that cultivate their identities: their places in various social institutions and in various ideological formations" ( $p$. 333). Indeed, readers who engage in intentional reading practices employ text to gain knowledge and situate their learning within a broader realm of knowing. The deliberate exploration of text, especially when bound to the critical inquiry that can occur in book clubs, influences readers' values, philosophy, and, ultimately, identity. 
This study focuses on two book clubs, both initiated by and consisting of students enrolled in the Library and Information Science (LIS) Program at the University of Hawai' $i$ at Mānoa (UHM). The first was the Books by Women Book Club (BBWBC), premised on the feminist ideal and named after the group's mandate to focus on books written by women. While this group employed no formalized working definition of feminism, its principles and practices aligned with intersectional feminism ${ }^{1}$ (Crenshaw, 1989) and were established in recognition of the continuing systematic marginalization of women. In their own way, to counteract the publishing and book reviewing disparity between men and women (King and Clark, 2018), BBWBC members sought to support women writers by dedicating time to their work. In doing so, participants simultaneously increased their own exposure to women-authored texts and their awareness of the unequal status quo of the publishing industry. Beyond this single criterion for book selection (which applied to all but one book during the research period), BBWBC texts were deliberately inclusive: members selected books of a variety of genres and viewpoints written by and about women of various cultures, ethnicities, nationalities and places of residence, sexual orientations, ages, socioeconomic statuses, religions, experiences, and cis, trans, and genderqueer identities.

The second book club this study examines was the UHM LIS Book Club (LISBC). This group was a collaborative project started by two student groups at UHM: the LIS Diversity Council and the Progressive Librarians' Guild (UHM Chapter). This book club aimed to use reading and discussion to foster the UHM LIS community, and to encourage a progressive commitment to social justice in LIS via an appreciation of diversity. While most of the BBWBC texts were novels that could be considered pleasure reading, the LISBC texts tended to be more academic in nature and more visibly related to LIS. Participation in both book clubs was voluntary-members elected to read and meet of their own volition.

While the two book clubs began as separate and distinct groups, they started to converge as my data collection progressed. Because of the social interconnectedness of the UHM LIS community, some participants who were initially members of only one of the book clubs became aware ofand decided to join-the other as well, which can serve as a testament to the captivating nature of book clubs. More striking than the degree of membership confluence was the fact that participants referenced the respective values-feminism and diversity-of each book club with increasing frequency in the meetings of both. Because the textual content and discussion for the BBWBC and the LISBC were increasingly informed by each other's values, the resulting framework merged these values into a new schema-a feminist diversity ethic-which recognizes the interconnectedness of feminism and diversity (Bunch, 1992; O'Brien Hallstein, 1999). I define a feminist diversity ethic as a form of intersectional feminism that values experiential knowledge, the multifaceted nature of identity, respectful communication, caring, and orientation toward social justice as a means of dismantling interlocking systems of oppression. bell hooks (1989) argues:

Feminism, as liberation struggle, must exist apart from and as a part of the larger struggle to eradicate domination in all its forms. We must understand that patriarchal domination shares an ideological foundation with racism and other forms of group oppression, and that there is no hope that it can be eradicated while these systems remain intact (p. 22).

A feminist diversity ethic aligns with hooks' assertion, and maintains an embrace of diversity as an effective means of subverting and negating oppressions. While the feminist BBWBC contributed a focus particularly on gender and sex, the diversity and progressivism-oriented LISBC contributed a focus on cultural paradigms and identity. As these two groups began to

The International Journal of Information, Diversity, \& Inclusion, 3(1), 2019

ISSN 2574-3430, https://jps.library.utoronto.ca/index.php/ijidi 
influence each other, these two value sets came to bolster the intersectional framework with which participants interpreted feminist and diverse textual content. Commenting on the intentional selection of books for the inclusion of intersectional and feminist themes, one study participant shared:

I think it does change the discussion because we are a lot more aware of that issue going in, so when we look at the plot we look at it from a feminist perspective and not just as "Oh, I like this character"; "This plot is interesting"; but "What does this say about society and about the author who is writing it, and about how we react to these things?"

Indeed, their intentional reading practice became lived experience that in turn influenced members' perspectives. The book clubs' emphasis on a feminist diversity ethic informed members' approach to LIS in several key ways: first, it challenged participants to define diversity and its importance in LIS; second, it fostered the deconstruction of the notion of the other; and third, it enabled participants to actualize a feminist diversity ethic within the book clubs, thus preparing them to continue enacting this ethic in their future roles as LIS professionals.

With this study, I hoped to better understand the meaning and significance of participation in book clubs as a tool of educational, personal, and professional development. The world of scholarly research is rich with studies demonstrating the transformative nature of book clubs but markedly lacks studies exploring the experience of librarians in book clubs. This is surprising considering that librarians work closely with books and other media and that librarians serve as frequent facilitators of book clubs as part of their library programming (Irvin Morris, 2012).

I was especially interested in the experience of LIS students in book clubs, as an educational journey through an LIS master's program is a pivotal time in their professional lives. An LIS program is a transitional stage whereby students progress from non-professionals or paraprofessionals toward the role of a professional librarian. Exposed to the pedagogy of LIS and cognate disciplines, students are deeply immersed in the theory of the field without having achieved the status of a professional librarian. Within this liminal state, students are often just beginning to formulate and contextualize their professional LIS philosophies. The experiences students have in an LIS program have the potential to play an influential role in shaping their professional convictions and philosophies, and thus can reverberate throughout their entire careers.

\section{Background}

I approach the exploration of text in the social sphere-specifically in book clubs-through a social constructivist framework. Social constructivism is primarily concerned with the construction of meaning by individuals and groups. It is a theory of relativism, which holds that all meaning and knowledge are human constructions and that the objective truth is an impossibility. Au (1998) explicates that in the social constructivist framework, "communication or discourse processes are compared to processes of building, and generative acts" (p. 300). Rosenblatt's (1968) transactional approach to reader response theory is a natural extension of social constructivism to the realm of literature and reading. Rosenblatt established that readers engage in a transaction with text, whereby their interpretation of the text is informed by their personal experiences and patterns of thought. According to Rosenblatt, it is through this interaction between reader and text that unique meaning is engendered (1968). Thus, reading text presents an opportunity for the exploration of the internal self. If we extend this concept into the social, 
interpersonal realm, we see that when we engage others in conversation about text, we can explore our personal responses to literature in the context of the lived experiences and philosophies of others, in addition to our own.

Vygotsky's (1978) zone of proximal development (ZPD), in conjunction with Rosenblatt's transactional reader response concepts, provides an additional theoretical foundation to explain how group discussions of literature, in which individuals share their unique experiences with text, offer new insights into participating individuals and ultimately propel them to deeper, more dynamic understandings of text and self. Vygotsky understands the ZPD as the space between one's actual developmental level (ability to independently problem-solve) and one's potential developmental level (ability to problem-solve with guidance from or collaboration with a more capable other). When applied to reader response theory, the ZPD would exist between initial individual perceptions of a text and collaborative discussion of it with another. Book clubs construct a situation in which all members may potentially occupy both the teacher and the learner role at once, simultaneously traversing and helping others across the ZPD to arrive at new understandings of literature through discussion.

Many studies affirm that book clubs bring great benefits for their participants (Kooy, 2006; Fajardo, 2010; Polleck, 2010; Polleck, 2011). They provide participants with an inquiry-based experience in which dialogue-a collaborative interaction with texts and each other-enables new ways of seeing and relating to one's world. Kooy (2006) advances this argument in relation to the teaching profession. Her study demonstrates that interactions in book clubs composed of teachers constitute a mode of praxis. Her teacher participants were inspired by text to ruminate on their experiences engaging with real life situations in their professional spheres, and then to enact new teaching approaches based on the ideas presented in book club discussions. In a similar vein, Morris et al. (2006) and Irvin Morris (2012) connect the benefits of book club participation to LIS professional praxis. They emphasize that the librarian facilitation of book clubs enables the formation of closer connections with and deeper understanding of library patron communities. This, in turn, empowers librarians in their professional identities and in their roles as community advocates.

Book club interactions are advantageous to a range of participants-from casual readers to those invested in intensive professional praxis. What benefits can book clubs yield specifically for LIS students? This population is important to consider because, at the beginning of their LIS careers, students simultaneously engage with the established theory and practice of the LIS profession and seek to define their roles within it. In the following sections, I aim to investigate the experience of emerging LIS professionals at an especially pivotal time in their professional lives.

\section{Methods}

Data collection took place over four months, from April to August 2018. I conducted participant observations in a total of five book club meetings: two in BBWBC, two in the LISBC, and one final session in which both groups decided to meet together. Each book club met about once a month, with an average of four attendees per meeting. Meetings typically lasted between two and three hours. During my data collection, the LISBC read Blind Spot: The Hidden Biases of Good People by Mahzarin R. Banaji and Anthony G. Greenwald (2013), Americanah by Chimamanda Ngozi Adichie (2013), and Feminist Pedagogy for Library Instruction by Maria T. Accardi (2013). The BBWBC read The Year of Magical Thinking by Joan Didion (2007), A Darker Shade of Magic by V. E. Schwab (2015), Freshwater by Akwaeke Emezi (2018), and Redefining Realness: My Path to Womanhood, Identity, Love \& So Much More by Janet Mock (2014). 
I conducted individual interviews with six core book club members-those whose participation was most regular. Three of the interviewees were members of BBWBC only, one was a member of LISBC only, and two maintained memberships in both groups. Although there were two or three book club members in each group who participated on a semi-regular basis, I aimed to select regular participants as my interviewees. Since they consistently read the selected texts and attended the meetings, I believed that their accounts would be the most representative of the book clubs' importance and their influence on students and students' professional practice.

All participant observation sessions and individual interviews were audio-recorded. After each interaction, I transcribed the recordings and then read and analyzed them. Each time I analyzed a new transcript, I would also re-read and re-analyze the earlier transcripts, so that I could understand them as a cohesive body of data. This process aided the discovery of thematic topics in participants' conversations and modes of communication among participants. This reading and re-reading aided in data triangulation and also helped me to ensure consistency in data collection and interpretation. My participant observations and field note-taking allowed me to address my research questions contextually, as I became a first-hand witness to the processes, dynamics, and conversations of the book clubs. In complementary fashion, my interviews allowed my study participants to address my questions directly and openly, in their own words.

I had been a member of the BBWBC since its first meeting in the spring of 2017 and began my participant observation with the LISBC at its inaugural meeting in the spring of 2018. Central to ethnographic participant observation is the engagement of the researcher in the same processes they are studying and observing. As I assumed the role of a researcher and initiated my data collection, I adopted a less active role in book club discussions than I would have, had I not been conducting research. I did so in order to refrain from unduly influencing the course of dialogue. In an effort to fairly situate my claims, I am forthcoming about the possibility that my role as a participant observer strengthened book club members' commitment to a feminist diversity ethic, simply because I asked them to think about and articulate convictions developed in and through book club membership. I am confident, however, that through participation in book clubs, the value internalization would have occurred in any case, even without my presence; however, my research presence may have made these processes more explicit or expedited.

As a member of both book clubs, I was personally involved with both of my research populations. On the one hand, this presented an advantage because I already had access to these groups and was uniquely positioned to understand the context from which participants drew. On the other hand, however, this close involvement had the potential to become a barrier to fair and measured data interpretation. I was personally invested in these communities and deeply related to their core values. As a result, I had to consider the degree to which this would influence my perspective. I took special care to triangulate my findings; to control bias in data interpretation by engaging in a reflective journaling practice whereby, once a month, I responded to the same questions that I asked my interviewees. This allowed me to compare my responses to those of my interviewees and to evaluate how my perspective shifted over time. While acknowledging that total objectivity was impossible, I resolved to engage in reflective practices through which I continually examined my own convictions to remain aware of them at all times and to ensure that potential bias was minimized.

Finally, to protect participant confidentiality, I refer to my participants using pseudonyms.

The International Journal of Information, Diversity, \& Inclusion, 3(1), 2019

ISSN 2574-3430, https://jps.library.utoronto.ca/index.php/ijidi 


\section{Results}

Through this research, I sought to achieve an understanding of the creative, constitutive, and generative processes of BBWBC and the LISBC. The results of this study underscore three broad essential elements of student participation in these value-driven LIS book clubs: defining diversity, deconstructing the other, and embodying a feminist diversity ethic. The members of these book clubs defined and mastered a feminist diversity ethic. This ethic challenged them to elucidate diversity and its importance to them and to the field of LIS; to develop empathy and reject the idea of the other; and then to actually apply a feminist diversity philosophy to their interpersonal relationships, critical thinking, and the way in which they connected book club activities to their future professional practice. In subsequent sections, direct quotes from the observed meetings and interviews will illustrate the creative process of book club participation in members' own words.

Since participants selected particular books specifically for their ability to advance conversations on feminism and diversity, it was clear that they approached their individual reading practice with these values at heart. During the observed meetings, participants expressed the ways in which they connected textual content to their own lived experiences, values, and ideas, and eagerly listened to each other's contributions. Participants would often relate stories of their own personal and professional experiences brought to mind by the texts under discussion. For example, discussing Joan Didion's The Year of Magical Thinking, one book club member shared how reading about Didion's experience with grief had helped her to better understand her own partner's emotions related to an ailing parent. Similarly, a conversation on Chimamanda Ngozi Adichie's Americanah-whose protagonist is the strong, witty, and opinionated Ifemeluprompted participants to discuss how challenging it can be to approach people who have ideas that are antithetical to their own. One participant told an anecdote from her library internship, regretting that she did not advocate for open access in a conversation with a librarian who was dismissive of the idea. Although on the surface level, the conversation in meetings may have seemed to shift from topic to topic, at times, veering off substantially from the text in question, participants were actually creating a rich web of dialogue that contributed to their understandings of textual content. Even tangentially, participants were using the unique knowledge they had amassed through lived experience to push each other to deeper understandings of textual content. Through this process of sharing, participants also came to understand each other better, and to see more clearly how their personal experience had shaped everyone's worldviews.

\section{Defining Diversity}

Participants' exploration of diverse books was enhanced by their own multifaceted identities and diversity, which they came to understand in more holistic, comprehensive terms. All of the members of both book clubs were women-a factor that, alone, placed them outside the mainstream, dominant culture (Accardi, 2013). Aside from this shared characteristic, participants were different in many ways. Their ages ranged from mid-20s to mid-40s; they had spent varying lengths of time in the LIS program (from two to four semesters at the start of data collection); and they came from diverse educational backgrounds, including literature, social work, fashion design, international relations, and business. Three of the six interviewees had already earned another master's degree. Moreover, participants were able to contribute diverse life experiences and cultural knowledge which derived from the geographic diversity of their places of origin, including various U.S. states, East Asia, South Asia, the Caribbean, and Europe. Two participants who had lived their entire lives in Hawai' $i$ provided unique perspectives on their

The International Journal of Information, Diversity, \& Inclusion, 3(1), 2019 ISSN 2574-3430, https://jps.library.utoronto.ca/index.php/ijidi 
locality and relationships with Hawai' $i$, remarkable for its demographic diversity. Members were also able to offer multiple perspectives informed by the diversity of personal identities, sexual orientations, ethnic, racial, and religious backgrounds, and experiences with homelessness. Although participants enjoyed a higher level of education than is typical of the Hawai' $i$ population (Research and Economic Analysis Division, Hawaii State Department of Business, Economic Development and Tourism, 2016), Hawai'i's diverse character was otherwise well represented by this group.

One member, Selma, attributed the learning she was able to accomplish within the book clubs to the manifold identities of her book club peers:

I have learned that I have a lot to learn. It helps that we have a diverse little group in terms of sexual orientation, age, educational background, et cetera. Those different experiences make me learn a lot and it helps me to learn why people had different reactions to books than I did. It gives me ideas or considerations I wouldn't have or didn't come to on my own.

Selma credited the book clubs not for their surface-level representation of diversity, but for the ability of diverse perspectives to impel readers toward more comprehensive understandings of both text and human experiences. Rather than accepting surface-level conceptions of diversity, the book clubs encouraged members to advance their personal definitions of diversity, expanding and refining where necessary, so that their new thoughtful and comprehensive understandings would carry weight, engender new commitment, and likely have a lasting impact on how they approach their LIS work. While they may not always gain the same access to others' stories as they did in the tight-knit book club communities, participants will have a deeper appreciation of other people's unique stories and diverse individual identities.

Reading, however, is a sure way to gain access to stories, experiences, and ideas that others choose to share. It is an immersive experience that allows readers to temporarily inhabit the minds, imagination, and lifeworlds of others (real and fictional characters; narrators; authors; etc.). As a result, reading is an effective channel by which readers can learn to recognize the multidimensional nature of our distinct and varied identities beyond surface-level diversity characteristics (Irvin, 2016). Those who acquire a deep appreciation and mastery of reading have an opportunity to remedy the widely internalized tendency to judge others based on observable characteristics.

An opportunity to look beyond the surface allowed participants to examine more closely the values with which they identified, and to reflexively question where they came from, and why. Book club conversations elucidated that a single term, "feminism," for example, can have widely different interpretations by different people. Exposure to multiple interpretations of the same term encouraged critical and reflective thinking.

"Diversity" has proven to be a particularly tricky term, and some participants commented that the more frequently the term is used, the less it means. When Pennelope and I were discussing the concept in our interview, she related it to her learning from an LIS class:

We were talking about this [in class]; how "diversity" becomes this catch phrase that starts to lose its meaning the more you use it. So when we're talking about diversity, we're talking about anything outside of what is-what has been-a mainstream perspective; so like cisgender, white, straight, male gaze, I guess. It's such a wide 
all-encompassing thing for such a tiny word.

Selma, for instance, refused to settle for a single, final definition of diversity, emphasizing instead the need for the term to be inclusive and flexible: "I feel like you need to take a kaleidoscopic view of it because there are so many ways to be diverse that I don't think it can be just reduced to one trait or characteristic." In this conversation, I asked Selma whether she felt that her definition of feminism, too, had morphed throughout her book club participation. She began to discuss how the book clubs often challenged her notions of feminism. As a result of participating in the book clubs, she said, her take on feminism had become more fluid.

One of the BBWBC texts, Book of Joan by Lidia Yuknavitch, is a dystopian science fiction novel that questions and problematizes the significance of sex and gender. In the book, following a near total destruction of the Earth, the few surviving humans have transformed into entirely sexless beings whose skin has blanched to an almost transparent white. They live above the desecrated planet suspended on a platform called CIEL. Selma described Book of Joan as "one of, if not the most, overtly feminist books that we've read." Selma, who identifies strongly as a feminist, was surprised at her own reaction to the text. She shared that

That was the book I hated. . . . I would say that I think it challenged my view of feminism, because I'm still not sure why I was so averse to that book. I guess it's made me seek out different viewpoints than my own. . . . I know we [book club members] all agree on basic things, like we are all feminists, but I guess it's made me more aware of the possibility for gray area within it, or nuance within it.

Commenting on the book's treatment of sex and gender issues, Selma continued:

It made me think way more about trans stuff. Trans people, trans rights, trans issues and trans portrayal in media. I've definitely encountered that and thought about it more from this book club. . . than probably ever before.

The BBWBC focus on gender and sex initially inspired members to listen only to women's voices; however, their evolving principle of inclusivity later prompted them to search for authors who existed beyond the heteronormative. Following Book of Joan, BBWBC opted to read two books in tandem for a subsequent meeting. The first was Akwaeke Emezi's Freshwater, which technically broke BBWBC's rule of reading only women-authored texts but was praised by the members for many reasons. In this autobiographical novel (Emezi, n.d.), Ada, a human girl, is born with spirit entities who are cognizant and active within her mind. As she grows up, these entities crystallize into more powerful selves who assume increasing control over Ada. Through her protagonist, Emezi reveals much of herself. We learn that Emezi does not identify only as human, but also as Ogbanje, an odinani term for a malicious spirit that plagues the human family into which it is born. In her essay entitled "Transition" (2018), Emezi writes: "I exist separate from the inaccurate concept of gender as a binary; without the stricture of those categories, I don't even have to think about my gender. Alone, there's just me, and I see myself clearly." Members were appreciative of such narrative paradigms.

For the same meeting, BBWBC decided to combine their reading of Freshwater with the reading of Redefining Realness: My Path to Womanhood, Identity, Love \& So Much More by Janet Mock, which did not fall in the category of works authored by women. In this stunning memoir, transgender rights activist Janet Mock relays her story of arriving at her identity and becoming self-empowered. 
BBWBC members purposefully selected texts that included portrayals of women with equally diverse empowered identities. Then in meetings, the way that women with such an array of experiential knowledge shared their interpretations of texts made these texts even more powerful. The texts became an inspiration for participants to stretch their ideas of feminism and diversity to new, more inclusive dimensions. Moreover, it was important that participants consider the ideas of feminism and diversity in tandem, as book club members came to recognize their interconnectedness and mutual dependency. A focus on diversity contributed to an intersectional understanding of feminism. A focus on feminism contributed to the validation of experiential knowledge and equity.

These new, complementary understandings of feminism and diversity bolstered participants' ability to critically evaluate written materials. As a result, they felt that it would translate into a valuable skill in professional practice that will help them, in the future, to better evaluate library resources for the equitable and respectful representation of diverse perspectives. On this topic, Romy shared that participation in the book clubs was "encouraging us to think more critically about all aspects of LIS and how we can make sure that we are being inclusive and promoting diversity." In line with Balderrama's (2000) assertion that "appropriate tension and constructive conflict can occur if we are willing to go through it rather than around it" (p. 207), the book club members chose to openly engage with questions of identity, privilege, and equity with the intention of developing and strengthening their critical thinking.

\section{Deconstructing the Other}

Reading and subsequent discussions of texts related to diversity and feminism can mitigate the effect of othering, whereby individuals construct artificial boundaries between different groups of people. Beyond recognizing more expanded and elastic definitions of diversity, the book clubs allowed members to collectively step out of their own comfort zones.

Bossaller, Adkins, and Thompson (2010) explain that even the best intentions of being inclusive do not prevent people from acting "through the mores and values" of their own culture (p. 33). Dissociating from their own worldview may be a near-universal challenge for those seeking to embrace a diversity ethic.

The book club members engaged in critical, reflective, and reflexive reading as a means of overcoming this challenge. Despite diverse backgrounds, participants nevertheless recognized that they must be proactive and tenacious in order to see beyond their own limited perspectives. They realized that continuous and concerted effort is required in order to get out of the "bubble." Books selected for reading enabled participants to deconstruct the artificial barriers between the familiar and the unfamiliar, thereby dismantling the notion of the other. On this topic, Pennelope was especially enthusiastic about her book club reading experience:

I think I read somewhere that it's easier to change views when you're looking at fiction because you empathize with the character so it's kind of like walking a mile in someone's shoes kind of thing. And as opposed to like, looking at a textbook and looking outside in, you'd be looking inside out at an issue, which I feel like maybe we should do, because that's why patrons go to the library, right? . . . It's easy to forget that the books aren't just like these physical objects, they're like an experience for the users. So . . . how can we look at the issues from the user perspective? But also, how can we use these to change things for the community from this perspective where people can empathize? 
At once, Pennelope considered the influence that an intentional reading practice had on her own ability to think empathically, and then applied this notion to an imagined library community. She asked how LIS professionals could effectively support a reading practice that would foster empathy and the deconstruction of the other on a larger scale.

In one BBWBC example, the "other" took the form of Joan Didion, an author and a narrator of the nonfiction book The Year of Magical Thinking. This narrative challenged participants to reconsider some of their own anxieties and judgements. In this book, Didion takes us through an intimate account of the year following the death of her husband, John Gregory Dunne. The Year of Magical Thinking was so valuable because Didion countered the tendency of mainstream American society to avoid discussing death, dying, and grieving in relaying her intimate processes facing these realities. While engaging with these topics initially made most participants uneasy, participants ultimately affirmed that the processes of reading and discussing the text alleviated their discomfort. Rather than reacting with fear, as they did at first, participants seemed pleased to arrive at a profound appreciation of Didion's invitation to meditate on death and grief and to experience them through her story. As Selma said, "I wish there were more books like this because I think it's super important just to know. This is such a private experience, normally." By allowing participants to express anxieties provoked by reading in a receptive and encouraging environment, book club discussion worked to alleviate participants' fears.

Participants believed that the remarkable change in their willingness to engage these topics would translate into an increased ability to empathize with those experiencing loss and grief. There was overwhelming agreement among BBWBC that our cultural norm is to feel encumbered and inconvenienced by others' feelings of sadness, and thus to avoid them. The group seemed to agree that, in the future, they would be able to empathize more easily with those who grieve. In more general terms, BBWBC members found an intentional reading practice to be an effective way of enhancing their capacity for empathy and of breaking down the barriers between self and other.

Similarly, the LISBC accepted a challenge to critically examine their own views by reading and discussing Blind Spot: The Hidden Biases of Good People by Mahzarin R. Banaji and Anthony G. Greenwald. In this nonfiction text, the authors explain implicit bias-the idea that all of us have biases of which we are not aware; these biases may influence our behavior toward certain groups of people. The group collectively argued that it is important to recognize our bias in order to find a way of changing our exclusionary thinking into more inclusive one. Selma stressed a physiological basis for understanding bias, saying that "it's the way that the brain works, because you have to learn how to operate within a system." By engaging with texts espousing diverse perspectives, participants sought to familiarize themselves with alternate "systems" and integrate the variant thinking into their own. Selma elaborated, "I think this [Blind Spot] is a good book for librarians because . . . it really comes down to exposure." She argued that it is "so easy to vilify what you don't know. And as soon as you can humanize something, it's just totally different." This was a central shared aim of both book clubs: to become comfortable with the unfamiliar-a process that transforms the "other" into something relatable, which is especially crucial in people-oriented professions like LIS.

\section{Embodying a Feminist Diversity Ethic}

By intentionally ruminating on feminism and diversity-their meanings and implicationsparticipants became better prepared to incorporate these ethics into their professional practice. The book club processes moved these values from the realm of theory to the realm of practice. 
In our interview, when I asked Pennelope whether she would have approached LIS with feminist and diversity lenses without the book club experience, she replied:

Probably, but ... it would be a more empty answer without the book clubs, because we've had all these discussions. I think you can say it and think that you're going to do those things in the profession, but when you have these discussions on the regular, it changes those words, I hope, into action.

Moreover, the structure of the book clubs as co-curricular, alternative learning spaces represented an embodiment of a feminist diversity ethic. Akira, for example, described BBWBC as having "a very calm and relaxed atmosphere where I can interact with my peers in a more informal setting than a classroom." Indeed, largely because of their feminist frameworks, the book clubs facilitated friendships in ways that the traditional classroom does not. The social structure of the book clubs was lateral; some members took a more active role in logistical organization than others but everyone enjoyed equal opportunities to contribute to conversations and exchange knowledge and experiences.

Central to an embodiment of a feminist diversity ethic was the respectful way in which book club members related to one another. According to Noddings (1984), an ethic of care emphasizes interpersonal relationships rooted in receptivity and responsiveness. In the book club context, an ethic of care and the sharing of personal narratives had a reciprocal effect whereby both mutually reinforced other another. Participants approached each other with care and compassion from the start, laying the foundation that enabled all participants to feel comfortable enough to share and dialogue with each other while creating personal connections. Although participants did not always agree with each other, they did feel that they trusted each other enough to have a respectful and constructive conversation and share personal stories. As Romy commented,

One of my favorite things about books is sometimes it feels like I read a completely different book than someone else, just because our perspectives on it are so different-it's almost a completely different story. And I know everyone brings in their own life experience and their own professional experience, so everyone is going to have something different-a different interpretation, or take, on it.

Sharing implies vulnerability because it requires revealing personal details about people's lives and experiences, and it is particularly important to have trusted individuals at the discussion table. Sharing, in turn, reinforced a sense of intimacy within the group. The system was selfreinforcing and demonstrated to participants how a feminist diversity ethic can successfully enhance group learning.

\section{Discussion and Ideas for Future Research}

While I initially viewed the small number of participants in my study as a limitation, through the process of participant observation and data analysis, I ultimately came to understand it to be an advantage: fewer individuals at select meetings enabled those who were present to engage in more focused conversation on certain topics. This study illustrates that book clubs composed of a small number of participants may present environments conducive to conversation and learning, especially for those who are hesitant or shy about participating in larger social groups.

Similar studies, however, have included greater numbers of participants, and have been successful in making more generalizable conclusions as a result. Smith's (1996) study of book 
club interactions, for instance, included two book clubs comprised of six and 12 individuals, respectively. Beach and Yussen (2011), who sought to identify factors that contribute to the enduring nature of book clubs, studied two book groups, comprised of seven and nine individuals, respectively. In these two examples, sample sizes were large enough to support the legitimacy of the authors' conclusions, but still sufficiently small that they allowed for in-depth content analysis of interviews, thus producing rich, valuable insight on the process-oriented questions of the researchers.

Seeking to emulate the success of Smith, Beach, and Yussen, my future studies might aim to consult a greater number of participants, ideally across a longer time period, in order to better understand the dynamics of book clubs and their influence on future professional careers. Follow up studies could additionally seek to conduct comparative interviews or surveys in the crosssection of LIS-oriented book clubs, in different LIS programs, and/or among professional librarians. They could also follow up on the professional activities of current book club participants. This could lend credibility to the proposition that student book clubs make a significant contribution to their professional development and future careers.

During the meetings, participants often discussed the potential influence of the "echo chamber effect" upon group opinions. Participants were concerned that surrounding themselves only with like-minded individuals could lead to a limited view of the world, whereby personal opinions are simply reflected back rather than challenged. To counter the potential effect of the echo chamber, future studies could explore book clubs composed of LIS students or librarians who adhere to different and even conflicting philosophical perspectives.

\section{Conclusion}

Because the BBWBC and the LISBC together encouraged the juxtaposition of divergent and nuanced ideas derived from both texts and lived experiences, participants learned to become more intellectually critical and more thoughtful as human beings. These two characteristics will certainly help them in the future, as they start practicing reference services, readers' advisory, collection management, and community advocacy; it will also aid their collaboration with colleagues.

I will note that participants' willingness to engage with diverse content may have been encouraged by the broader cultural context of Hawai' $i$, of which ethnic and cultural diversity are integral and essential parts. However, even outside of Hawai' i, book clubs that emphasize diverse contents and respectful dialogue can be effective means of encouraging empathy toward and the appreciation of similarities and differences in the human experience and professional practice. Book clubs composed of diverse members and privileging multiple voices and individual stories are uniquely positioned to contribute to participants' inclusive thinking and critical thinking. Reading, in turn, is an effective entry point into diversity discussions, which can be strengthened by adding feminist perspectives with their integral values of caring, compassion, and equality.

\section{Acknowledgements}

I would like to thank Dr. Vanessa Irvin for her guidance throughout the research process, and Dr. Rich Gazan and Thomas Fielding for their insightful feedback on drafts of this article. I would also like to thank the IJIDI reviewers and Dr. Keren Dali for their suggestions for improving this paper and for offering their inspired ideas on directions for future research. 


\section{Endnotes}

1 Intersectional feminism acknowledges that overlapping identities-such as race, sex, gender, sexual orientation, class, age, and ability-are interconnected. It seeks to understand how interlocking systems of power marginalize socially stratified, interwoven identities. With a focus on intersectionality, feminism becomes more inclusive.

\section{References}

Accardi, M. T. (2013). Feminist pedagogy for library instruction. Sacramento, CA: Library Juice Press.

Au, K. H. (1998). Social constructivism and the school literacy learning of students of diverse backgrounds. Journal of Literacy Research, 30(2), 297-319.

Balderrama, S. R. (2000). This trend called diversity. Library Trends, 49(1), 194-214.

Beach, R., \& Yussen, S. (2011). Practices of productive adult book clubs. Journal of Adolescent \& Adult Literacy, 55(2), 121-131.

Beard, D., \& Thi-Beard, K. V. (2008). Rethinking the book: New theories for readers' advisory. Reference \& User Services Quarterly, 47(4), 331-335.

Bossaller, J., Adkins, D., \& Thompson, K. M. (2010). Critical theory, libraries and culture. Progressive Librarian, 34-35, 25-38.

Bunch, C. (1992). A global perspective on feminist ethics and diversity. In E. B. Cole \& S. Coultrap-McQuin (Eds.), Explorations in feminist ethics: Theory and practice (pp. 176185). Bloomington, IN: Indiana University Press.

Crenshaw, K. (1989). Demarginalizing the intersection of race and sex: A Black feminist critique of antidiscrimination doctrine, feminist theory and antiracist politics. University of Chicago Legal Forum, 1989(1), 139-167.

Emezi, A. (n.d.). Biography. Retrieved from https://www.akwaeke.com/biography

Emezi, A. (2018). Transition. Retrieved from https://bit.ly/2E1s4wE

Fajardo, A. (2010). Book clubs: Not just for public libraries. College \& Undergraduate Libraries, 17(1), 65-69.

hooks, bell. (1989). Talking back: Thinking feminist, thinking black. Boston: South End Press.

Irvin, V. (2016). Gazing the diversity stance in North America: Bringing practitioner inquiry into the LIS classroom. Journal of Education for Library and Information Science, 57(2), 151-160.

Irvin Morris, V. (2012). Reading in mirrors: Using street literature to facilitate practitioner 
inquiry with urban public service librarians (Doctoral dissertation). Retrieved from ProQuest Dissertations \& Theses Global. (3538166)

King, A., \& Clark, S. (2018, June 17). The 2017 VIDA count. Retrieved from http://www.vidaweb.org/the-2017-vida-count/\#Highlights

Kooy, M. (2006). Telling stories in book clubs: Women teachers and professional development. New York: Springer Science+Business Media.

Morris, V., Hughes-Hassell, S., Agosto, D. P., \& Cottman, D. T. (2006). Street lit flying off teen fiction bookshelves in Philadelphia public libraries. Young Adult Library Services, 5(1), 16-23.

Noddings, N. (1984). Caring: A feminine approach to ethics and moral education. Berkeley: University of California.

O’Brien Hallstein, D. L. (1999). A postmodern caring: Feminist standpoint theories, revisioned caring, and communication ethics. Western Journal of Communication, 63(1), 32-56.

Polleck, J. (2010). Creating transformational spaces: High school book clubs with inner-city adolescent females. High School Journal, 93(2), 50-68.

Polleck, J. (2011). Adolescent literature book clubs: A forum for cultivation of peer relationships with urban adolescent females. The ALAN Review, 39(1), 76-93.

Research and Economic Analysis Division, Hawaii State Department of Business, Economic Development and Tourism. (2016). Education attainment in Hawaii [PDF file]. Retrieved from https://bit.ly/2CGI9dj

Rosenblatt, L. (1968). Literature as exploration. New York: Noble and Noble.

Smith, M. W. (1996). Conversations about literature outside classrooms: How adults talk about books in their book clubs. Journal of Adolescent \& Adult Literacy, 40(3), 180-86.

Vygotsky, L. S. (1981). Mind in society: The development of higher psychological processes. Cambridge, MA: Harvard University Press.

Laila Brown (lailab@hawaii.edu) is a Library \& Information Science master's candidate at the University of Hawai'i at Mānoa. Her thesis research focused on how participation in book clubs that espouse a feminist and/or diversity ethic inspire LIS students to create deeper, more insightful connections between feminism, diversity, and LIS. A strong proponent of book clubs and a member of several herself, Laila Brown hopes to continue further research in this vein. She is an advocate for open access and particularly enjoys working with special library collections. She received a B.A. in Anthropology and B.A. in International Relations from the University of Southern California. 